\title{
Pit depth quantification of PM Aluminum Composites using Scanning Electron Microscopy and Image Analysis
}

\author{
N. Martínez, D. Busquets, V. Amigó, M.D. Salvador and N.Valero \\ Universidad Politécnica de Valencia. DIMM. Camí de Vera s/n, 46022 Valencia, Spain
}

Image analysis is an appropriate tool to characterize qualitatively and quantitatively the corrosion behavior in aluminum matrix composites. Localized corrosion (pitting) of these composites can be explained by calculating the amplitude of the developed pits as well as their depth ${ }^{1-5}$.

The growth of pits in samples of an aluminum alloy reinforced with intermetallic particles in marine solutions was studied in the present contribution. Localized corrosion was assessed by cyclic polarization tests and the microstructure of corroded samples was carried out using a JEOL 6300 SEM and Visilog 5.0 image analysis software. The corroded samples were examined using both backscattered electron (BSE) and secondary electron (SE) imaging modes. The SE imaging (Fig. 1.) allowed quantifying the dimensions of the pits that are presented on the samples. The BSE imaging (Fig. 3.) allowed determining pit depths in the cross-sectional corroded samples.

We show the development of a method of image analysis that allow us:

1- Quantify the dimensions of the developed pits, Fig. 1. For these propose, we will employ the command Area of Interest Measurement (AOIM), selecting the interested area on the sample, Fig. 2. With the statistical and mathematical tools is possible to calculate the area and perimeter of the pit that corresponds to an area of $2217.90 \mu \mathrm{m}^{2}$ and a perimeter of $1004.29 \mu \mathrm{m}$ of a total area of $512 \times 368$ pixels or $188416 \mu \mathrm{m}^{2}$ (calibration parameter: 51 pixels $=50 \mu \mathrm{m}$ ). We can employ the command Measure to calculate the amplitude of the pit. We calculated several diameters that include the pit $(\mathrm{d} 1=45 \mu \mathrm{m}, \mathrm{d} 2=45 \mu \mathrm{m}, \mathrm{d} 3=47 \mu \mathrm{m}, \mathrm{d} 4=58 \mu \mathrm{m}$ and $\mathrm{d} 5=50$ $\mu \mathrm{m})$ and finally the average diameter can be calculated: $d=45 \mu \mathrm{m}$, Fig. 2 .

2- Determine pit depth of corroded samples. The employed tools are basically the same, but in this case we will analyze the BSE image of a cross-section of the sample, Fig. 3. We select the pit zone and apply the AOIM command to select the area of study, Fig. 4. As a result we obtain a pit depth of $70 \mu \mathrm{m}$.

\section{References}

[1] S. Journaux, C. Guillaumin, P. Gouton, M. Paindavoine and G. Thauvin, Optical Engineering. 38 (1999) 1312.

[2] A. Sehgal, D. Lu and GS. Frankel, Journal of Electrochemical Society. 145 (1998) 2834.

[3] S. Mathis and M. Coster, Microscopy Microanalysis Microstructures. 7 (1996) 527.

[4] T. Shibata, Corrosion. 52 (1996) 813.

[5] H. Kamide and T. Mochida, Journal of the Japan Institute of Metals. 59 (1995) 1253. 


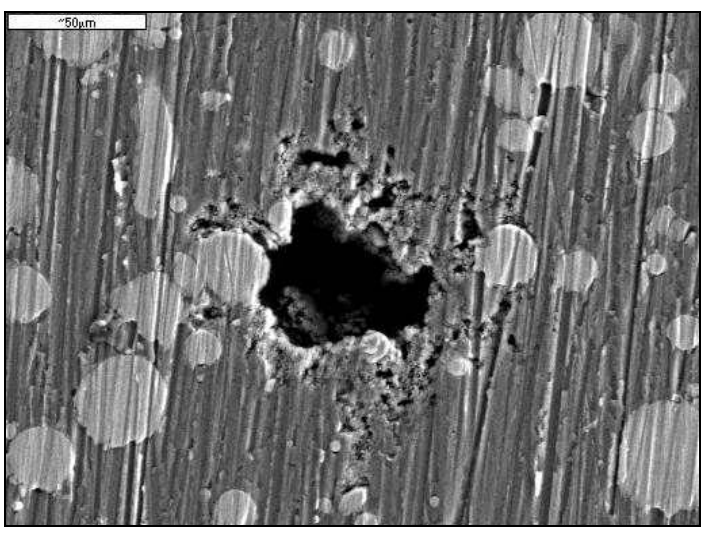

FIG. 1. SE micrograph at $500 \mathrm{X}$. Aluminum composite reinforced with intermetallic particles after $\mathrm{CP}$ test.

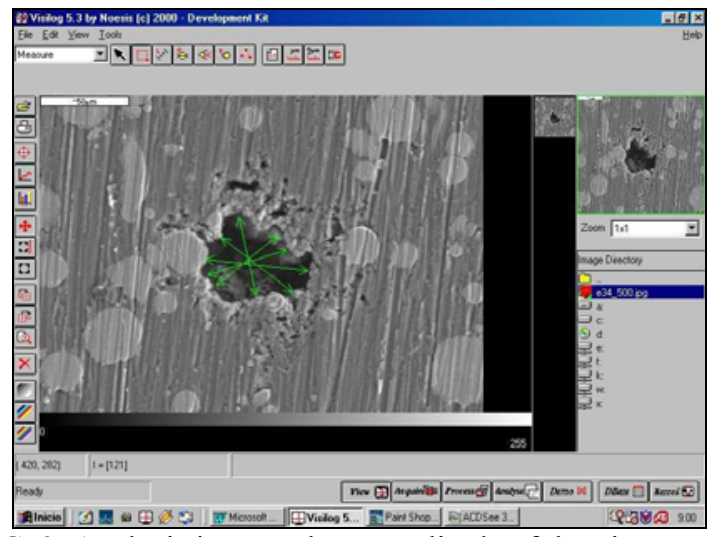

FIG. 2 Analysis image where amplitude of the pit are calculated.

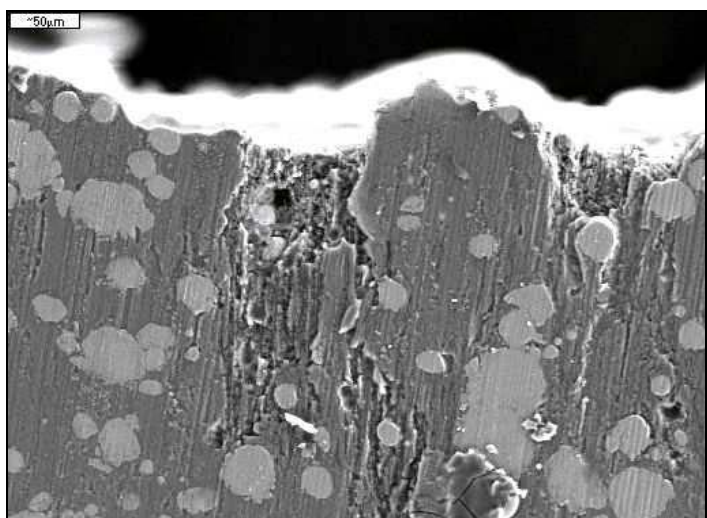

FIG. 3 BSE micrograph at 500X. Cross section of a corroded composite.

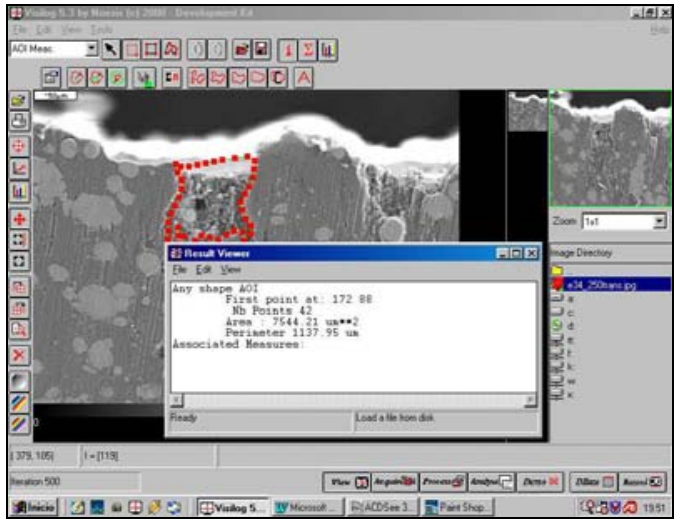

FIG. 4 Analysis image where the depth of the pit is calculated. 